\title{
Mobile phone and adolescents- addiction a mindful check in!
}

\author{
K.A.Sudhen Sumesh Kumar MSC (N) \\ Lecturer, School of Nursing and Midwifery, Haramaya University, Ethiopia \\ E-mail: getsumesh2007@gmail.com
}

\begin{abstract}
Mobile phones, one of the greatest inventions in the late 20th century, now have become the newest addiction in the world. Even though it has given us convenient and comfort, it doesn't mean it has no adverse effect. It is something that is going to affect everyone on day to day basis. The concept and ideas of the adolescents with mobile phone use and mental health generated a possible pathway for personnel dependency and also for the direct sources of stress, depression, sleep disturbances, aggression, and to a list of risky behaviors. However, studies on the association between problematic mobile phone use and psychological problems have been relatively few until now. The impact of mobile phone in adolescents in different domains of mental health should be considered for epidemiological and interventional studies.
\end{abstract}

Keywords: Adolescents, Cell Phone Use [CPU], Mobile Phone, Mobile Phone Use [MPU], Psychological Problems.

\section{Introduction}

According to the American society of Addiction Medicine, Addiction is a primary, chronic disease of brain reward, motivation, memory and related circuitry. Dysfunction in these circuits leads to characteristic biological, psychological, social and spiritual manifestations. This is reflected in an individual pathologically pursuing reward and/or relief by substance use and other behaviors. Nowadays, addiction not only refers to drug or substance abuse, but it also refers to gambling, internet, games, or even smart phones. These also fall under the category of behavioral addiction (Lee YS 2006, P. 209).The conventional diagnostic system strictly regards only symptoms caused by repetitive and excessive substance use as addiction. However, not only average people but even clinicians use the term 'addiction' when a person is obsessed with a certain activity that results in disturbance of his/her daily activities and shows a pattern similar to substance dependence. The classic example of this activity is gambling. In the conventional diagnostic system, gambling is classified as an impulse control disorder; but after continuous studies on its similarity with substance addiction, it was considered as addiction in the DSM-5 based on the results of studies on its neurobiological and psychopathological evidence. Recently, it has been reported that internet based activities such as gaming; chatting and pornography have been showing similar levels of addiction as those of drug and substance abuse. (Kwon M et al. 2013)

In Recent years Mobile phone use (MPU) is an important part of life for many people. However, there have been increasing numbers of studies indicating that problematic MPU may complicate physiological and psychological problems (Croft RJ et al. 2002, Hamblin DL et al. 2004, Lajunen HR et al. 2007). Mobile phone use has become widespread among children and adolescents, with surveys finding 76\% mobile phone ownership in Hungary, 79\% mobile phone access in Sweden and $94 \%$ ownership in Germany (Mezel G et al. 2007, Sodrqvist F et al. 2007,Thomas S et al. 2010). The ratio of adolescent users is estimated to have further increased (Labode V 2011, P.65) and politicians, public health officials and the scientific community show an increasing interest in the relation between children and adolescents' health and radiofrequency radiation (RFR) exposure (Wiedemann P et al. 2011, P. 226). A bibliometric analysis which was done in 2009 , on the studies which were published all over the world on the addiction to the internet, video games and mobile phones, showed that the latter constituted only $2.1 \%$ of the studies (Carbonell X et al. 2009 , p. 102). No discussion on the proliferation of mobile phones would be complete without addressing the negative impact of mobile phone use on the quality of life of bystanders. From obnoxious ringtones to unavoidably overheard conversations, the use of mobile phones in public has, from the perspective of many, become highly problematic. (Patrick et al. 2008, P.177)

\section{Mobile phone and adolescents}

In general, adolescence is a critical transition for mental and physical development with vulnerability to ecological changes. Risktaking had been proposed as a common tendency in adolescence and some scholars regard it as one of the processes of normal development (Irwin CE 1989, P.122). However, dangerous risktaking that takes place when normal adolescent testing goes awry and an adolescent becomes locked into a pattern with largely negative consequences has been termed 'risky behavior' (Ponton L 1997). A series of risky behaviors may be noted in an adolescent during the period of adolescence and compromise the adolescent's development. Furthermore, there was an explanatory psychosocial framework conceptualized by Jessor (Jessor R 1991, P. 597-605) which was based on the web of causations theory (Macmohan B et al. 1960) to facilitate the understandings of adolescent risky behaviors. To our knowledge, there has been a lack of studies to survey the association between problematic MPU and risky behaviors in adolescents (Yang et al. 2010, P.217). However, a recent report from the National Academy of Sciences recommends that this issue be further studied, especially in light of increasing use of mobile phones by children. (McCartt AT et al. 2006, P.89) 


\section{Mobile phone and radiofrequency radiation}

A recent review on epidemiological studies shows no or only limited evidence on the effects of RFR on the incidence of brain tumors and leukemia in children as well as cognitive and other brain functions in children. (Wiedemann P et al. 2011, P. 226) Children and adolescents start to use mobile phones at an earlier age compared to adults, in a period when the plasticity of their brain continues (NRC 2008). The exposure to RFR still continues to have a high research priority according to the new World Health Organization (WHO) research agenda (Lonn S et al. 2005 \& Lahkola A et al. 2007). Indeed, a recent study has found an increased risk of glioma among people who had started to use mobile phones under the age of 20 (Klaeboe L et al.2007, P.158).

\section{Impact of mobile phone usage}

Mental disorders account for a large proportion of the disease burden in young people in all societies, and are a global public health challenge (Hepworth S et al. 2006, P. 883). The causes of mental disorders are multi-factorial, and cultural factors seem to have an influence. One of the major changes in the exposure profiles of young people is the use of information and communication technology (ICT). In 2007, $75 \%$ of 16- to 24-year-old Swedes used the inter-net every day, and more than $90 \%$ had a computer at home (Interphone study Group I 2010, P. 675). Almost all had a mobile phone. In a qualitative study, Gustafson et al (IARC 2011) explored young adults' experience, attitudes and health beliefs in relation to information technology use and found that they perceived both opportunities and including risks to physical and psychosocial health. In respective studies of physiological complications, the carcinogenic effects of MPU are still controversia (Laviola G et al.1999 \& VanDeventer E et al. 2011), while the thermal (Roosli M et al. 2010, P. 887) and non-thermal effects (Patel V et al.2007 \& Carlberg M et al. 2012) of MPU have been confirmed. Previously researchers have found that problematic MPU was associated with low self-esteem in adult populations (Sweden Statistics 2007) in addition to alcohol drinking (Gustafson E et al. 2003, P. 565) and depression (Moulder JE ET al.2005, P.189) in Adolescent populations.

In recent years, a psychological problem which results from the excessive use of mobile phones which is called "Ringxiety" has been reported. It is a condition where individuals hear the phone ringing when it actually hasn't, which is also called "phantom ringing" (Kan $\mathrm{P}$ et al.2008, P. 71). It has been estimated that $25 \%$ of the mobile phone users in India could be suffering from this disorder (Frey AH 1998, P. 101). Excessive mobile phone use has been found to be associated with headache, stress, sleep disturbances and depression (Borbely AA et al. 1999, Binachi A et al.2005, Zhao TY et al. 2007). A cross-sectional study was carried out at Kasturba Medical College, Mangalore, south India, among 336 medical students by using a pre-tested, semi-structured questionnaire. Among the total number of students, 335 students possessed mobile phones. Mostly, the persons whom they talked to on their phones were parents for $220(51 \%)$ of the students. $48 \%$ (150) talked for less than half hour in a day and $41 \%$ (137) were high volume message users. "Ringxiety" was experienced by $34.5 \%$ (116) of the students and they were more likely to use their phones at restricted places like classrooms (99\%) and libraries (60.3\%). A significantly larger proportion of ringxiety sufferers also complained of hampered studies. The pattern of mobile phone use among the medical students appeared to be problematic, as a fairly large proportion suffered from ringxiety, they reported getting very upset and they used their phones at restricted times and places.(Leena K et al. 2005,P.35).
Table 1: Pattern of Mobile Phone Use by the Students

\begin{tabular}{|c|c|c|}
\hline Call duration/day in minutes & no. & $\%$ \\
\hline$\leq 30$ & 150 & 48.4 \\
\hline $31-60$ & 66 & 21.3 \\
\hline $61-120$ & 51 & 16.5 \\
\hline$\geq 121-300$ & 43 & 13.9 \\
\hline Total & 310 & 100.0 \\
\hline number of messages sent per day & & \\
\hline 0 & 17 & 5.1 \\
\hline $1-5$ & 68 & 20.3 \\
\hline $6-10$ & 55 & 16.4 \\
\hline $11-20$ & 58 & 17.3 \\
\hline$>20$ & 137 & 40.9 \\
\hline Total & 335 & 100.0 \\
\hline \multicolumn{3}{|l|}{ time of maximum use } \\
\hline Morning & 23 & 6.1 \\
\hline Afternoon & 12 & 3.2 \\
\hline Evening & 161 & 42.8 \\
\hline Night & 180 & 47.9 \\
\hline Total & 376 & 100.0 \\
\hline \multicolumn{3}{|l|}{ Mode of use } \\
\hline Ringing & 133 & 39.7 \\
\hline Vibrating & 122 & 36.4 \\
\hline Silent & 79 & 23.6 \\
\hline Switch off & 1 & 0.3 \\
\hline Total & 335 & 100.0 \\
\hline \multicolumn{3}{|l|}{ time spent on other features } \\
\hline$<1 \mathrm{hr}$ & 167 & 49.9 \\
\hline $1-2 \mathrm{hrs}$ & 66 & 19.7 \\
\hline$>2 \mathrm{hrs}$ & 24 & 7.5 \\
\hline don't use at all & 77 & 23.0 \\
\hline $\begin{array}{l}\text { Total } \\
\text { use at Place/situation }\end{array}$ & 335 & 100.0 \\
\hline Classroom & 320 & 95.5 \\
\hline Library & 202 & 60.3 \\
\hline Eating & 219 & 65.4 \\
\hline Driving & 60 & 17.9 \\
\hline
\end{tabular}

Table -2: Association of Ringxiety with Patterns of Use $\begin{array}{llll}\text { Ringxiety } & & & \\ \text { Present no } & \text { Absent } & \text { Chi square } & \text { P value } \\ (\%) & \text { no }(\%) & \text { value } & \end{array}$

\begin{tabular}{|c|c|c|c|c|}
\hline \multicolumn{5}{|c|}{ takes to classroom } \\
\hline Yes & $114(99.1)$ & 201(93.5) & & \\
\hline No & $1(0.9)$ & $14(6.5)$ & & \\
\hline Total & $115(100)$ & $215(100)$ & 5.497 & 0.019 \\
\hline \multicolumn{5}{|c|}{ uses while driving } \\
\hline Yes & $25(22.5)$ & $31(14.6)$ & & \\
\hline No & $87(77.7)$ & $181(85.4)$ & & \\
\hline Total & $112(100)$ & $212(100)$ & 3 & 0.08 \\
\hline \multicolumn{5}{|c|}{ uses in library } \\
\hline Yes & $79(68.7)$ & $118(55.4)$ & & \\
\hline No & $36(39.3)$ & $95(44.6)$ & & \\
\hline Total & $115(100)$ & $213(100)$ & 5.5 & 0.019 \\
\hline \multicolumn{5}{|c|}{ uses while eating } \\
\hline Yes & $83(72.8)$ & $130(61)$ & & \\
\hline No & $31(27.2)$ & $83(39)$ & & \\
\hline Total & $114(100)$ & $213(100)$ & 4.533 & 0.033 \\
\hline \multicolumn{5}{|c|}{ if borrowed money without parents' knowledge for phone use } \\
\hline Yes & $27(23.9)$ & 24(11.4) & & \\
\hline No & $86(76.1)$ & $187(88.6)$ & & \\
\hline Total & $113(100)$ & $211(100)$ & 8.696 & 0.003 \\
\hline \multicolumn{5}{|c|}{ Whether students cut sleep to talk on mobile } \\
\hline Yes & $17(14.8)$ & $12(5.6)$ & & \\
\hline No & $98(85.2)$ & $203(94.4)$ & & \\
\hline Total & $115(100)$ & $215(100)$ & 7.915 & 0.005 \\
\hline \multicolumn{5}{|c|}{ Call duration /day in minutes } \\
\hline$\leq 30$ & $53(47.7)$ & $100(49.3)$ & & \\
\hline $31-60$ & $17(15.4)$ & $49(24.1)$ & & \\
\hline $61-120$ & $21(18.9)$ & $30(14.8)$ & & \\
\hline$\geq 121$ & $20(18)$ & $24(11.8)$ & & \\
\hline Total & $111(100)$ & $203(100)$ & 5.414 & 0.144 \\
\hline
\end{tabular}

\section{Mobile phone and stress}

The dominant concept in interviews regarding mobile phone use was the perception by participants of demands and expectations that they be available every- where and at all times. This could 
lead to high quantitative use, including interruptions of work, sleep, and other activities, the annoyance of disturbing ring signals, the feeling of never being free, and difficulties separating work from leisure. Some experienced having so many phone calls and SMS messages that they could not make time to answer them all, which led to stress or even feelings of guilt. Participants felt that they were generally expected to explain whenever they were unavailable to answer a call or message. Furthermore, the flexibility of mobile phones could imply fragmentation - being overbooked and not being able to postpone. Feelings of dependency or compulsiveness in relation to the mobile phone were described, including the compulsion to check the display and feelings of high stress when not reachable (forgetting the phone at home, for example, or running out of battery power or calling range). Physical reactions, such as headaches or heat sensations after prolonged use, were also stressful and led to worries about possible hazards of electromagnetic radiation. Bad qualitative use (destructive communication or information received via the mobile phone) could also be a stressor. Relationship stress was also mentioned, in terms of the possibility of one partner keeping secrets through communications on their private phone, leading to jealousy in the other.

User competence problems mentioned as stressful included handling all the functions of the phone or trying to keep up with the latest models. Other issues were costs, worry about losing the phone, and keeping the battery charged. All but one of the respondents had ideas about associations between mobile phone use and stress, although several could only identify those associations concerning other persons. The mobile phone was considered not only to increase, but also to decrease stress because of the flexibility it provides. Some insisted that not having access was the main stressor. (Yen CF et al. 2007, P. 863).

\section{Mobile phone and depression}

A possible pathway to depression was considered to be via stress and sleep disorders, and it was suggested that the demand for constant availability could interfere with recovery. Unreturned calls or SMS messages could lead to feelings of guilt. There was also a notion that not being available could lead to being left out. Social isolation was more evident when the phone didn't ring. It was also suggested that mobile phone use might decrease personal contact in real life and thus increase social isolation. The quality of information or communication received via mobile phone could be destructive; for example, negative information received at the wrong time and place, or harassing phone calls or messages. It was considered easier to send negative messages (breaking up a relationship, for example) via SMS than to deliver them face to face, and so there was a perception of a higher risk of receiving bad information via mobile phone than receiving it through other channels. Jealousy in relation to others' phone use was also mentioned, as were feelings of inadequacy in response to receiving messages about others' good fortune. Electromagnetic radiation was suggested as another link to depression. (Avvannavar SM et al.2008, P.82).

\section{Mobile phone and sleep disorders}

A high quantity of phone calls and messages in general was perceived to lead to difficulties relaxing, and therefore to too little sleep or decreased quality of sleep. A high number of messages that had not been replied to could also lead to overload and feelings of guilt. Long phone calls before bedtime could influence sleep negatively, because of headaches or tension. However, the most obvious aspect connecting mobile phone use with sleep disturbances was being awakened at night by phone calls or messages. This meant waking up, checking the phone, and most likely answering or replying to a message. Even with the sound switched off, one could be woken by the sound of a vibrating phone or even by a blinking light. Some felt obliged to check the phone if they woke up at night Other factors that were seen as possible contributors to sleep disturbance were communications with disturbing content, the thoughts provoked by a call or SMS, electromagnetic radiation, and worry about such radiation.(Avvannavar SM et al.2008, P.82).

In the study to find the association between problematic cellular phone use and risky behaviors and low self-esteem among Taiwanese adolescents. The problematic CPU was associated with insomnia in all groups of adolescents. Meanwhile, problematic CPU was associated with short nocturnal sleep duration in all groups of adolescents except for in girls 15 years or older. With a characteristic of being without predefined stopping points, intensive CPU may lead directly to a reduction in total sleep time by substituting for it. It may also be the contents of CPU that provokes sleep problems. Late and exciting CPU can cause high arousal and alertness in the brain, thus interfering with the calming effects that are necessary for sleep and delaying the onset of sleep (Sinha K 2007).

\section{Mobile phone and aggression}

In the study to find the association between problematic cellular phone use and risky behaviors and low self-esteem among Taiwanese adolescents. we found a positive association between problematic CPU and aggression perpetration and victimization among all adolescent groups of different genders and ages. The problematic CPU has extended interpersonal contacts which increased the risk to expose themselves with physical conflict to others. There were positive association between aggression involvement and internalizing and externalizing problems. (Oftedai $\mathrm{G}$ et al.2000, P. 237) Problematic CPU and aggression involvement, as well as other risky behaviors, might be the results of chaotic lifestyles. Thirdly, because most of the adolescents have no economic autonomy to buy their own cellular phone and to pay the monthly rental fee, the risk of involvement in interpersonal entanglement of money with subsequent violent aggression and victimization may increase. (Sinha K 2007).

\section{Mobile phone and unprotected sex}

In a recent study that problematic CPU was associated with unprotected sex in all adolescent groups except boys younger than 15 years. Although the causality could not be determined in this study, one possible explanation for the association was that the extension of interpersonal networks by CPU may increase the opportunities for close contact with potential sexual partners. (Sinha K 2007).

\section{Mobile phone and other risky behaviors}

Recent studies found that problematic CPU was associated with tattooing in all groups except for in girls 15 years or older. Meanwhile, problematic CPU was associated with previous criminal record in boys but not in girls. Additionally, problematic CPU was associated with suspension from school in boys 15 years or older. Tattooing is traditionally considered a form of deviant behavior in many Asian countries. The associations of problematic CPU with tattooing, suspension from school, and criminal records might further support that problematic CPU is a manifestation of disorganized lifestyles in adolescents. However, the association between problematic CPU and tattooing was not significant in the girls 15 years or older. One explanation is that girls of 15 years or older may have greater concern about the disfiguring effects of tattooing than the other groups of adolescents. Meanwhile, gender and age may have moderating effects on the association between problematic CPU and suspension from school and previous criminal record. Research also found that intensive CPU was associated with smoking cigarettes and excessive alcohol consumption. Previous study results showed that adolescents with significant de- 
pression were more likely to have problematic CPU (Moulder JE et al. 2005, P. 189), which might partially account for the associa- tion between problematic CPU and suicidal tendencies. (Sinha K 2007).



Fig. 1: A Model of Possible Path for Associations between ICT Use and Mental Symptoms. The Proposed Model Is Based on the Concepts and Ideas Expressed by the Young Adults Perceived Connections between Information and Communication Technology Use and Mental Symptoms Among Young Adults a Qualitative Study (Sara Thomee Et Al. 2010, P.66).

\section{Conclusion}

Even through Mobile phone is quite important for many different field of professions, entertainment of mobile phone is now overstep its basic needed in daily life. This article concludes the effects of possible addiction and alarms considering that psychological addiction have been described as a true disorder and the pending possibility of physiological addiction as a real disorder. Let's make one thing clear, Mobile phones are here to stay. In lieu of all of the evidence provided funding for education on proper cell phone use needs to be implemented to help avoid possible physiological and psychological disorders. Cell phones are a great technology, "They're useful in a lot of situations. (But) one of the most important things is making sure you have some cell phone free time in your day. It's OK to turn it off. Focus on family, homework, knowing that cell phone message will still be there."

\section{References}

[1] Lee YS (2006) Biological model and pharmacotherapy in Internet Addiction, Journal of Korean Medical Association 49(3):209-214

[2] Kwon M, Kim D-J, Cho H \&Yang S (2013) The Smartphone Addiction Scale, Development and Validation of a Short Version for Adolescents. PLoS ONE 8(12)

[3] Croft RJ, Chandler JS, Burgess AP, Barry RJ, and Williams JD \& Clarke AR: (2002) acute mobile phone operation affects neural function in humans. International Journal of Clinical Neurophysiology, 113(10):1623-1632.
[4] Hamblin DL, Wood AW, Croft RJ \& Stough C(2004) Examining the effects of electromagnetic fields emitted by GSM mobile phones on human event-related potentials and performance during an auditory task. International Journal of clinical Neurophysiology, 115(1):171178.

[5] Lajunen HR, Keski-Rahkonen A, Pulkkinen L, Rose RJ, Rissanen a \& Kaprio J (2007) Are computer and cell phone use associated with body mass index and overweight? A population study among twin adolescents .BMC Public Health, 7:24

[6] Mezel G, Benyi M \& Muller A (2007) Mobile phone ownership and use among school children in three Hungarian cities, Bio electro Magnetics , $28: 309-315$

[7] Söderqvist F, Hardell L, Carlberg M, and Mild k H (2007) Ownership and use of wireless telephones: a population-based study of Swedish children aged 7-14 years. BMC Public Health, 7:105.

[8] Thomas S, Heinrich S, Kühnlein A, and Radon K (2010) the association between socioeconomic status and exposure to mobile telecommunication networks in children and adolescents. Bioelectromagnetics, 31:20-27.

[9] LaBode V (2011) Text messaging: one step forward for phone companies, one leap backward for adolescence. International Journal of Adolescent Medical Health, 23:65-71.

[10]Wiedemann P, Schütz H (2011) Children's health and RF EMF exposure. Views from a risk assessment and risk communication perspective. Wien Med Wochenschr, 161:226-232

[11]Carbonell X, Guardiola E, Beranuy M \& Bellés A (2009) a bibliometric analysis of the scientific literature on Internet, video games, and cell phone addiction. Journal of Med Libr Assoc. 97(2): 102-07

[12]Patrick et al, (2008) Health and the Mobile Phone, Am J Preventive Med. 35(2): 177-181.

[13] Irwin CE Jr (1989) Risk taking behaviors in the adolescent patient: are they impulsive? Pediatric Ann, 18(2):122. 124, 125. 
[14]Ponton L (1997) The Romance of Risk: Why Adolescents Do the Things They Do New York: HarperCollins.

[15]Jessor R (1991) Risk behavior in adolescence: a psychosocial framework for understanding and action. Journal of Adolescent Health, 12(8):597-605.

[16]Mac Mahon B, Pugh TF \& Ipsen (1960) Journal of Epidemiological Methods Little, Brown

[17]Yang et al (2010), The Association between problematic cellular phone use and risky behaviours and low esteem among Taiwanese adolescents, BMC Public Health 2010,10:217

[18] McCartt AT, Hellinga LA, \& Bratiman KA (2006), Cell phones and driving: review of research. Traffic Inj Prev; 7(2):89-106.

[19] National Research Council. Identification of research needs relating to potential biological $r$ adverse health effects of wireless communication devices. Washington DC: The National Academies Press (2008)

[20]Lonn S, Ahlbom A, Hall P \& Feychting M (2005) Long-term mobile phone use and brain tumor risk. American Journal of Epidemiology 161:526-535.

[21]Lahkola A, Auvinen A, Raitanen J, Schoemaker MJ, Christensen HC, Feychting M, Johansen C, Klaeboe L, Lönn S, Swerdlow AJ, Tynes T, \& Salminen T ( 2007) Mobile phone use and risk of glioma in 5 North European countries. International Journal of Cancer, 120:1769-1775.

[22] Klaeboe L, Blaasaas K, \& Tynes T (2007) Use of mobile phones in Norway and risk of intracranial tumours. European Journal of Cancer Prevention, 16:158-164.

[23]Hepworth S, Schoemaker M, Muir K, Swerdlow A, Tongeren M \&McKinney P (2006) Mobile phone use and risk of glioma in adults: case-control study. BMJ, 332:883-887.

[24]Interphone Study Group I (2010): Brain tumor risk in relation to mobile telephone use: results of the INTERPHONE international casecontrol study. International Journal of Epidemiology, 39:675-694.

[25] International Agency for Research on Cancer: IARC classifies radiofrequency electromagnetic fields as possibly carcinogenic to humans, Press release No: 208. Lyon: World Health Organization; 2011.

[26]Laviola G \& Adriani W (1999) Psychobiological risk factors for vulnerability to psychostimulants in human adolescents and animal models. Neuroscience Biobehavioural Rev 23:993-1010.

[27]Van Deventer E, van Rongen E \& Saunders R (2011) WHO research agenda for radiofrequency fields. Bioelectromagnetics, 32:417-421.

[28]Roosli M, Frei P, Mahler E, \& Hug k (2010) Systematic review on the health effects of exposure to radiofrequency electromagnetic fields from mobile phone base stations. B World Health Organ, 88:887-896.

[29]Carlberg M \& Hardell L (2012) on the association between glioma, wireless phones, heredity and ionizing radiation. Pathophysiology, 19:243-252

[30]Patel V, Flisher AJ, Hetrick S \& McGorry P (2007) mental health of young people: a global public-health challenge. Lancet, 369(9569):1302-1313.

[31] Statistics Sweden: Use of computers and the Internet by private persons in 2007.

[32]Gustafsson E, Dellve L, Edlund M \& Hagberg M (2003) the use of information technology among young adults-experience, attitudes and health beliefs. Applied Ergonomics, 34(6):565-570

[33]Moulder JE, Foster KR, Erdreich LS \& McNamee JP (2005) Mobile phones, mobile phone base stations and cancer: a review. Int J Radiat Biol, 81(3):189-203.

[34]Kan P, Simonsen SE, Lyon JL \& Kestle JR (2008) Cellular phone use and brain tumor: a meta-analysis. J Neuro oncol, 86(1):71-78.

[35]Frey AH (1998) Headaches from cellular telephones: are they real and what are the implications? Environ Health Perspective, 106(3):101103.

[36]Borbely AA, Huber R, Graf T, Fuchs B, Gallmann E \& Achermann P (1999) Pulsed high-frequency electromagnetic field affects human sleep and sleep electroencephalogram. Neurosci Lett, 275(3):207-210.

[37]Zhao TY, Zou SP \& Knapp PE (2007) Exposure to cell phone radiation up- regulates apoptosis genes in primary cultures of neurons and astrocytes. Neuroscience Letter 412(1):34-38.

[38]Bianchi A, Phillips JG (2005) Psychological predictors of problem mobile phone use. Cyberpsychol Behav, 8(1):39-51.

[39]Leena K, Tomi L \& Arja RR (2005) Intensity of mobile phone use and health compromising behaviors--how is information and communication technology connected to health-related lifestyle in adolescence? Journal of Adolescence, 28(1):35-47.

[40] Yen CF, Tang TC, Yen JY, Lin HC, Huang CF, Liu SC \& Ko CH (2009) Symptoms of problematic cellular phone use, functional impairment and its association with depression among adolescents in southern Taiwan. Journal of Adolescence, 32(4):863-873.

[41]Avvannavar SM, NandaKumar BS \& Shrihari S (2008) Mobile phones: an anthropological review of its Evolutionary impact. The Journal of International Social Research, 1(5):82-103
[42] Sinha K. Govt plans study on cell phone hazards [India] Available at: Times of India, Oct. 6, 2007 [Cited on 19 Mar 2011].

[43] Oftedal G, Wilen J, Sandstromt M and Mild KH (2000) Symptoms experienced in connection with mobile phone use. Occupational Medicine, 50(4): 237-45.

[44]Hocking B (1998) Preliminary report: Symptoms associated with mobile phone use. Occupational. Med.48(6):357

[45] Thomée S, Härenstam a \& Hagberg M (2011) Mobile phone use and stress, sleep disturbances, and symptoms of depression among young adults - a prospective cohort study. BMC Public Health; 11:66.

[46]Dr. Chetan Mandelia et al (2013) Ringxiety and the Mobile Phone Usage Pattern among the Students of a Medical College in South India. Journal of Clinical and Diagnostic Research, February, Vol-7(2): 205-209.

[47]Sara thomee, lotta Dellve, Annika Harenstam \& Mats Hagberg (2010) Perceived connections between information and communication technology use and mental symptoms among young adults, BMC Public Health, 10:66. 